\title{
THREE CASES OF INTRACRANIAL VASCULAR MALFORMATIONS IN INFANTS
}

\author{
BY \\ B. CORRIN \\ From the Children's Hospital, Birmingham*
}

(RECEIVED FOR PUBLICATION OCTOBER 18, 1958)

This paper is concerned with intracranial vascular malformations of hamartomatous origin and not with the relatively common aneurysmal, focal, intramural defects of the vessels of the brain. Such hamartomatous lesions have been well described (Cushing and Bailey, 1928 ; Lindau, 1931 ; Russell, 1931). They can be classified into three main types, namely $(a)$ haemangioblastomas, (b) cavernous angiomas, and (c) racemose angiomas. Haemangioblastomas usually occur within the cerebellum and often form a cyst with only a small nodule of tumour in its wall. They present as cerebellar tumours and may be associated with similar lesions in the retina and with cysts of the pancreas, kidney, or liver (Lindau's disease). Cavernous angiomas are usually situated within the substance of the brain and are similar in structure to the common cutaneous haemangiomas; occasionally they are associated with angiomatous lesions of the skin and other organs. The third variety is characterized by a mass of recognizable blood vessels in the pia arachnoid. These are variously named racemose angioma, cirsoid aneurysm, angioma venosum, angioma arteriale, or telangiectasis, depending largely upon the appearances at operation or necropsy. The three cases described in this communication had lesions of this third variety.

\section{Case Reports}

Case 1.-A baby girl was born at term and thrived for 42 hours. She then fed poorly and became restless with grunting respirations and rib recession. On the third day she developed cardiac failure. She was given digitalis but died when only 4 days old.

Necropsy Findings. - The body was that of a female baby with extremely livid skin and intense cyanosis of the lips and nail beds. The heart $(41 \mathrm{~g}$.) was almost twice the normal weight and both ventricles were dilated and hypertrophied. The common and internal carotid arteries were widened and thick walled. The caval veins and their tributaries were engorged and the lungs, liver, and

\footnotetext{
*Present address: Department of Pathology. Clinical Sciences
} Building, Manchester. kidneys were congested. The brain showed a dense mesh of small convoluted blood vessels in the pia arachnoid of the occipito-parietal regions, more marked on the left. The vein of Galen was greatly widened, measuring $1 \mathrm{~cm}$. in diameter, and drained into a large venous sinus occupying much of the posterior part of the posterior fossa. The sinus filled the angle between the tentorium cerebelli and the squamous part of the occipital bone; it received also the normal superior sagittal sinus, two large occipital sinuses, and hypoplastic straight and right transverse sinuses. The left transverse sinus was absent. Anteriorly the venous pool communicated with the sigmoid sinuses. On transecting the brain gross atrophy of the left occipital and parietal lobes, with thinning of the convolutions, was demonstrated (Fig. 1). These convolutions were of an opaque, rusty yellow colour and showed fine cystic degeneration, while the central white matter was soft and reddened and contained flecks of calcification. The left frontal and right occipital lobes were softened.

Histology.-All the viscera are intensely congested. The lungs show collapse, oedema, and occasional foci of inhalation pneumonia. There is fatty change in the periphery of the liver lobules, and the kidneys show fatty change in the convoluted tubules, with hyaline casts in the collecting tubules. The brain shows abundant, engorged blood vessels in the pia arachnoid of the left occipital and parietal lobes (Fig. 2) and, to a much lesser extent, of the other lobes. These blood vessels measure almost $1 \mathrm{~mm}$. in diameter and often present a bizarre configuration in transverse section. Some are thin-walled veins and others are arteries with a muscular media and an internal elastic lamina. The elastic lamina is frequently duplicated and irregular and the intima often shows focal collagenous proliferation (Figs. 3 and 4). These vessels do not penetrate the brain substance but give rise to a plexus of dilated capillaries in the pia mater (Fig. 5). The brain substance contains many engorged capillaries especially around the many areas of cystic change. The brain tissue of the left frontal and right occipital lobes shows early infarction, much oedema, vascular engorgement, and some perivascular haemorrhage. Swelling and disintegration of nerve cells are seen, with proliferation of foamy microglia. In the left parietal and occipital lobes it is barely possible to distinguish any resemblances to normal architecture. The cortical 


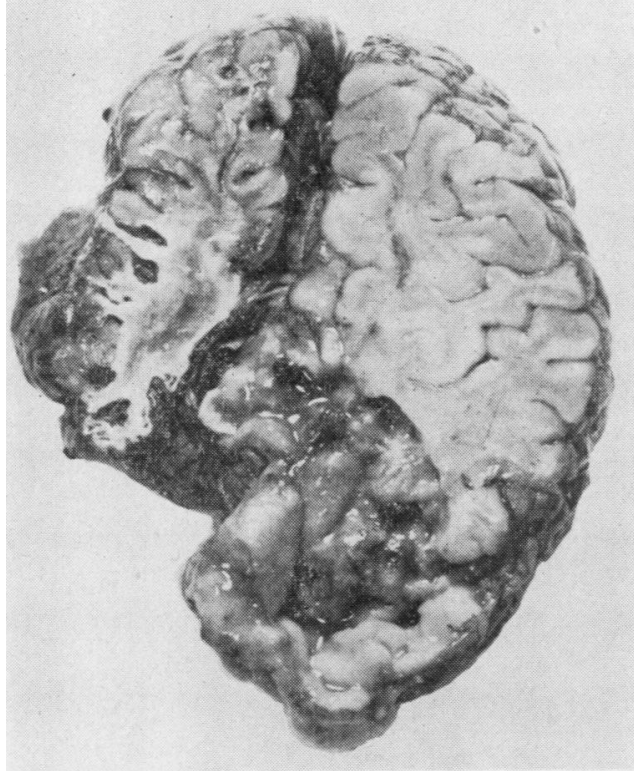

FIG. 1.-Case 1. Horizontal section of the brain showing atrophy of the left occipital and parietal lobes and thinning of the convolutions.

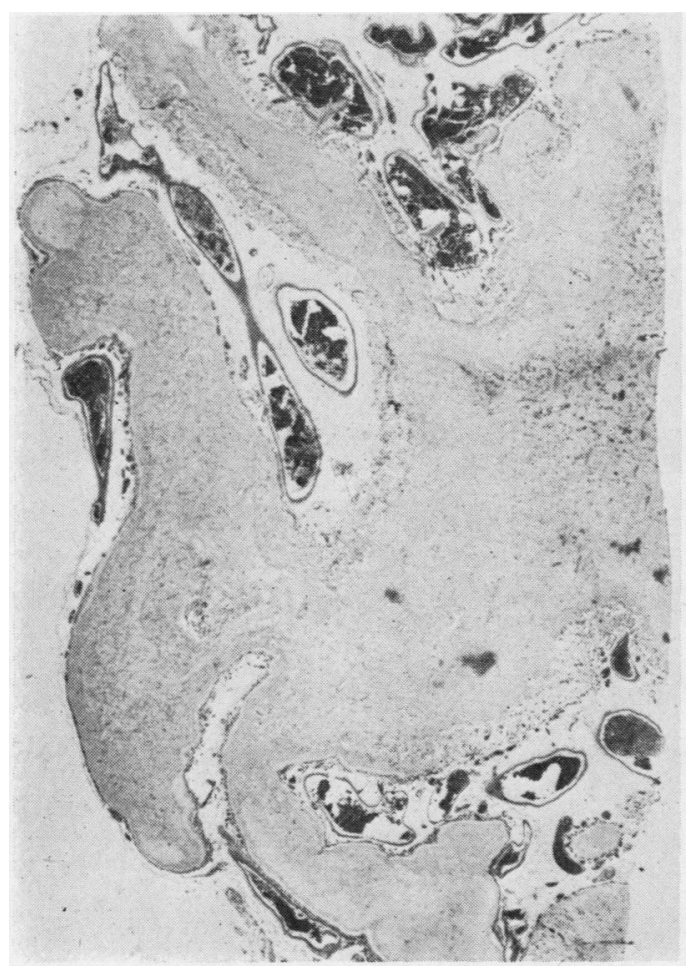

FIG. 2.-Case 1. Left occipital lobe showing many large engorged blood vessels in the pia arachnoid. There is thinning of the gyri and some focal calcification of the white matter. Haematoxylin and eosin, $\times 5.5$.

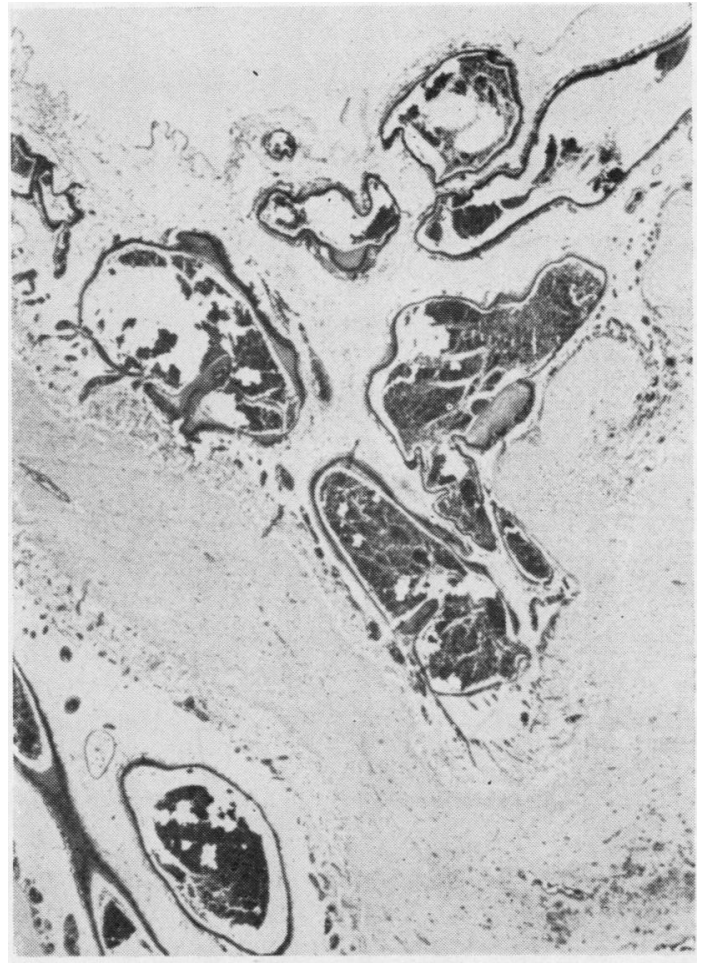

FIG. 3.-Case 1. Left occipital lobe. The arteries have a bizarre configuration on section and show focal intimal thickening. The pia mater is thickened and contains abundant engorged capillaries. Elastica van Gieson, $\times 11$.

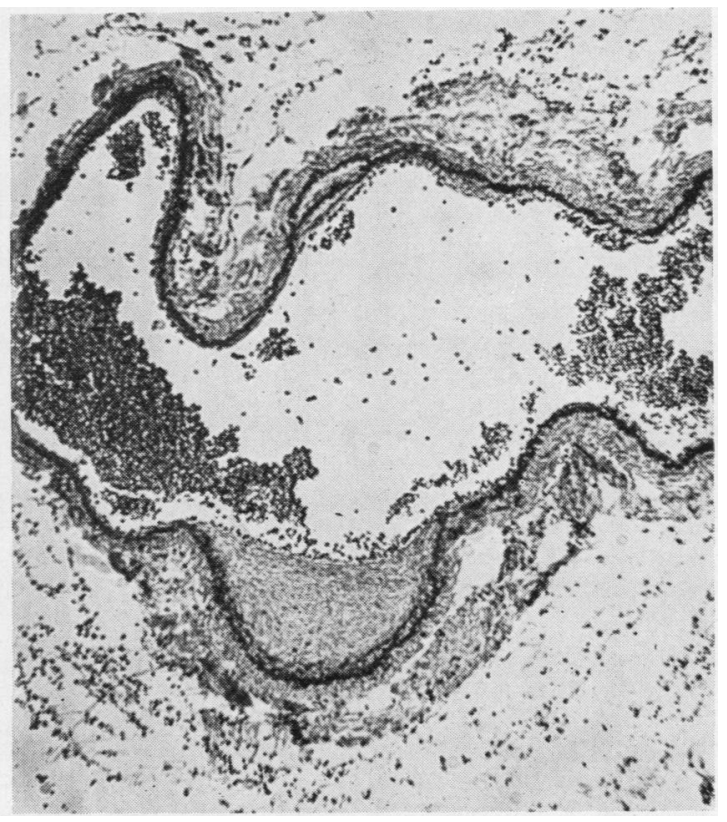

FIG. 4.-Case 1. Left occipital lobe. Reduplication of the elastic lamina and focal intimal thickening in one of the arteries Elastica van Gieson, $\times 100$. 


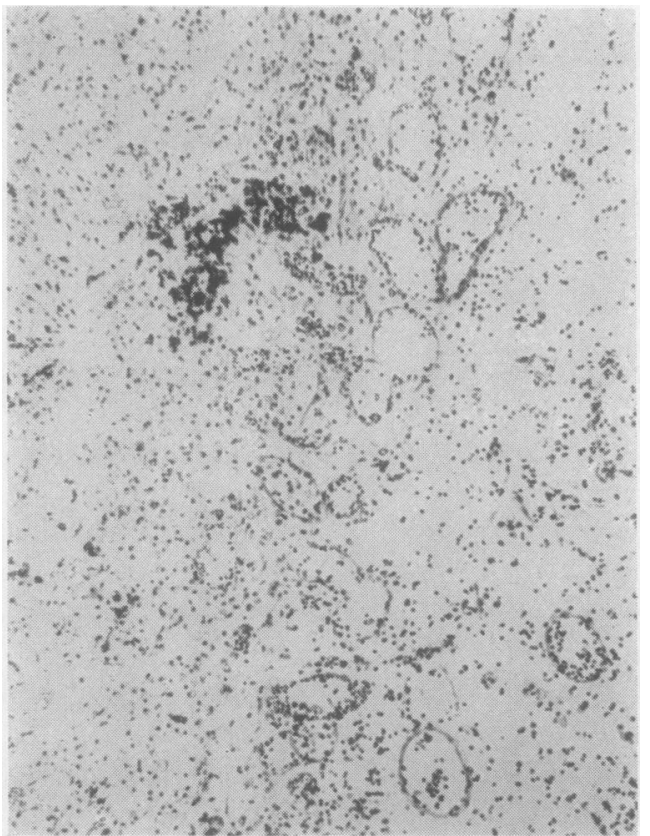

Fig. 5.-Case 1. Left occipital lobe. A capillary plexus in the pia mater. The underlying cortex contains foam cells and shows calcification. Haematoxylin and eosin, $\times 100$.

region shows extensive microcystic change with surrounding cellular astrocytic gliosis. The white matter shows dense astrocytic gliosis containing many foci of calcification; in a few places capillary walls are calcified (Fig. 6). Both cortical and medullary zones show occasional foci of haemosiderin and contain abundant fat-filled microglia (Fig. 7). There is no thrombosis in any of the sections examined. Apart from hypertrophy, no other significant change is seen in the walls of the internal carotid arteries or internal jugular veins.

Case 2.-The patient was a full-term baby boy who was regarded as normal until $2 \frac{1}{2}$ weeks of age, when at a welfare clinic a cardiac murmur was heard. At 3 weeks of age he was breathless and cyanosed, the heart and liver were enlarged, and there was a loud apical systolic murmur. Pulsation was noticed in the neck. In spite of digitalis therapy, he died in severe congestive cardiac failure when 7 weeks old. On the day of death the pulse was collapsing and there was marked pulsation on both sides of the neck; the systolic blood pressure was $130 \mathrm{~mm}$. $\mathrm{Hg}$ and the diastolic pressure could not be determined.

Necropsy Findings. - The body was that of a male infant of normal size for his age, whose lips and nail beds were cyanosed.

The heart $(65 \mathrm{~g}$.) was three times the normal weight, due to hypertrophy of both ventricles, which were dilated. Both common carotid arteries were wide and thick-walled. The jugular veins were engorged, the lungs oedematous and congested, and the liver and spleen congested.

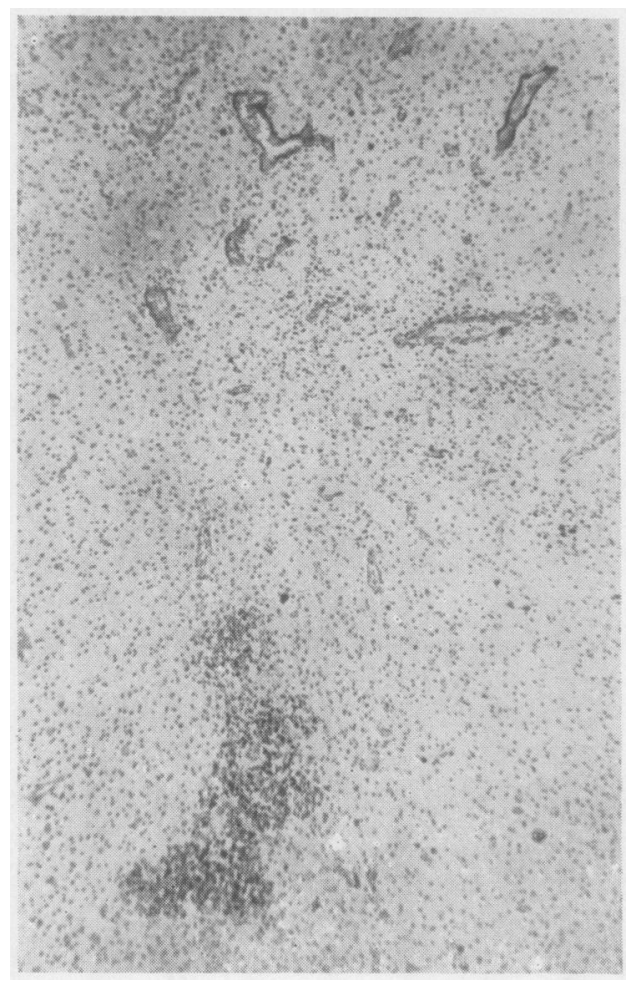

Fig. 6.-Case 1. Left occipital lobe. Astrocytic gliosis of the white matter with focal calcification. Many vessel walls are calcified. Haematoxylin and eosin, $\times 70$.

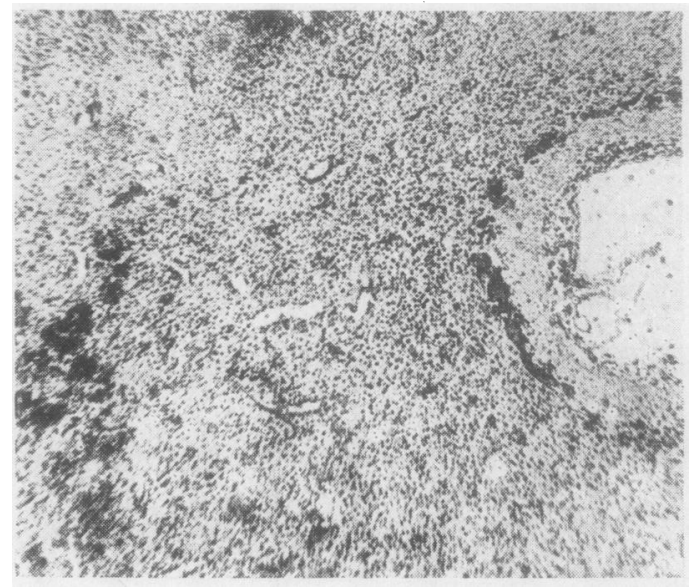

Fig. 7.-Case 1. Left occipital lobe. The base of a sulcus showing intracellular fat especially in the superficial cortex and subcortical white matter. Frozen section. Oil red $\mathrm{O}, \times 18$. 


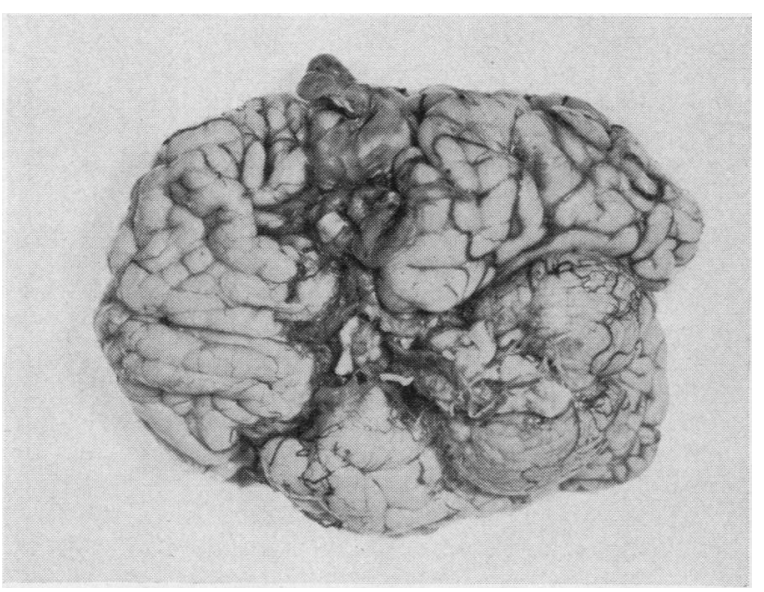

FIG. 8.-Case 2. The brain showing the racemose angioma in the left lateral central sulci.

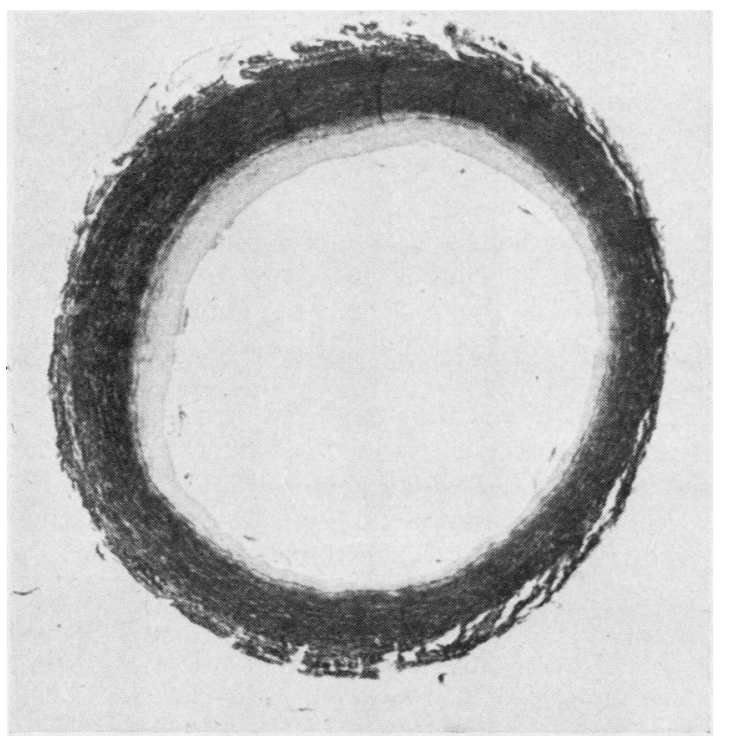

Fig. 9.-Case 2. Left common carotid artery showing thickening of the intima. Elastica van Gieson, $\times 11$.

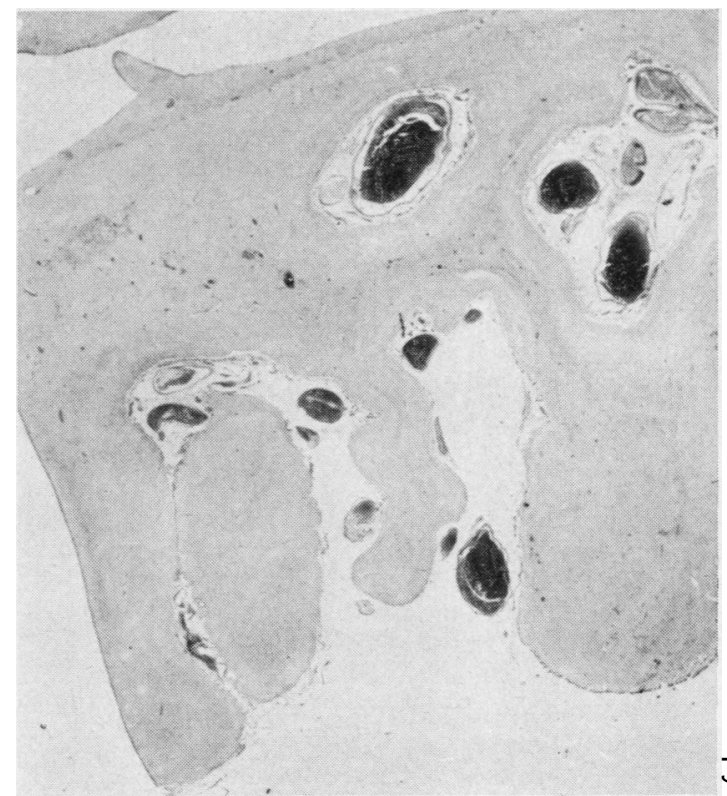

Fig. 10.-Case 2. Left parietal lobe. The gyri are shrunken and there are many large engorged blood vessels in the widened sulci. There is focal calcification in the underlying white matter. Thick cresyl violet, $\times 4$.

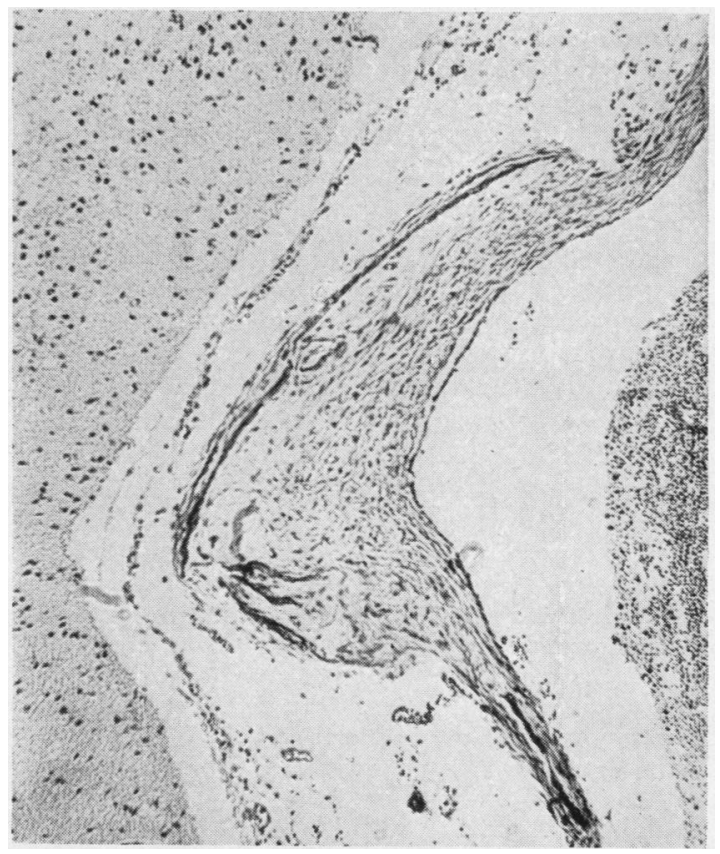

Fig. 11.-Case 2. Left temporal lobe. Focal intimal thickening with calcification and fragmentation of the elastic lamina. Haematoxylin and eosin, $\times 100$. 
A mass of wide convoluted vessels extended throughout the left lateral and central fissures from the base of the brain to the superior sagittal sinus (Fig. 8). The circle of Willis, the internal carotid, and the basilar arteries were dilated. The abnormal vessels drained freely into the superior sagittal sinus and also into the left transverse, left cavernous, and left sphenoparietal sinuses. The cut surface showed that the haemangioma extended down to the insula. The gyri of the opercula and insula were irregularly convoluted and thin. A narrow subpial zone of opaque pale yellow appearance could be traced round the margins of these atrophic gyri and there were small opaque creamy spots and flecks in the centre of the shrunken convolutions. There was marked atrophy of the brain tissue deep to the insula, the distance between the lateral ventricle and the external aspect of the insula being only $1 \mathrm{~mm}$.

Histology.-The liver shows congestion, centrilobular necrosis, and much fatty change in the intermediate zone. The lungs show much alveolar haemorrhage and oedema. The ventricles of the heart are hypertrophied, the right more so than the left. There is fibro-elastic thickening of the intima of both common carotid arteries (Fig. 9) and of the descending aorta. In the pancreas islet tissue is much increased. Some islets are only slightly enlarged, but there are sheets of confluent islets measuring up to $4 \mathrm{~mm}$. across. The islet cells, being grouped about a central capillary, present an illdefined pseudo-acinar structure; occasionally they appear to be arranged around a central lumen. The exocrine portion of the pancreas is normal. Pathological changes in the brain appear only in the area related to the vascular malformation in the left lateral sulcus. The abnormal vessels lie in the pia arachnoid and do not penetrate the brain substance. They consist of arteries with a welldefined elastic lamina and veins with only thin strands of elastin. These vessels are often of a bizarre configuration (Fig. 10). The arteries show focal fibrous thickening of the intima, sometimes with fragmentation and calcification of the elastic lamina (Fig. 11). Although it is possible to define cortical and medullary zones, the brain tissue shows extensive astrocytic gliosis, containing many vessels and foamy microglia. There are a few small calcific deposits in the white matter.

Case 3.- The patient was a female baby stillborn at 36 weeks' gestation. The mother had a threatened miscarriage at the end of the first trimester.

Necropsy Findings.-The body was that of a grossly malformed female baby with rotation of the trunk through 90 degrees. Much of the intestine and liver were visible within the sac of a large body stalk hernia. The umbilical cord was short $(14.5 \mathrm{~cm}$.) and contained only one artery.

The heart was normal in size and had a small high ventricular septal defect. The right renal artery arose from the superior mesenteric artery. The lungs were small and airless and no fissure separated the middle lobe. The intestines were obstructed, due to distortion within the hernial sac. The brain was of normal configuration, but both lateral fissures, the right more than the left, contained prominent, engorged, and convoluted blood vessels. Transection showed atrophy of the right insula and opercula and cystic softening deep to the insula (Fig. 12). There was no abnormality of the brain tissue bounding the left lateral fissure.

Histology. - The right lateral fissure of the brain contains many veins and arteries (Fig. 13). Mostly situated in the pia arachnoid, several penetrate the pial surface and extend into the brain substance (Fig. 14). The vessels are not thrombosed and none shows intimal thickening. The choroid plexus is greatly engorged. The cortex of the insula and frontal and temporal opercula has the highly convoluted appearance of microgyria (Fig. 13). The insula shows much astrocytic gliosis and contains small cysts, fatfilled microglia, and deposits of calcium. In the deep layers of the cortex there are many swollen degenerate nerve cells, some of which are undergoing phagocytosis. The underlying white matter is relatively intact but contains groups of small cells with prominent nuclei and nucleoli which are probably immature nerve cells (Fig. 14). There is slight proliferation of the subependymal glia.

\section{Discussion}

In reported series of intracranial tumours, those of vascular origin comprise from 1.4 to $5 \%$ (Cushing, 1932; Dandy, 1928 ; Walshe, 1931). Six are included in 171 cases of intracranial tumours in childhood studied by Bodian (1958). The three cases described in the present paper were necropsied within a few months of each other; but no other instances of intracranial haemangioma have been encountered in this department in the past five years, during which time approximately 1,500 necropsies have been done, mostly on stillbirths and neonates. This suggests that intracranial vascular hamartomas are rare in children.

About one-third of intracranial vascular tumours consist of the type described in the present paper (Cushing, 1932 ; Russell, 1931). It may be useful to summarize some of the features of 65 such cases reported in the literature (Alpers and Forster, 1945 ; Arieti and Gray, 1944 ; Bailey, 1948 ; Boldrey and Miller, 1949 ; Buckley, 1928 ; Byrnes and Boellaard, 1958 ; Campbell and Ballance, 1922 ; Craig, 1939 ; Cushing and Bailey, 1928 ; Dandy, 1928; Ford, 1952 ; Jaeger and Forbes, 1946 ; Lumsden, 1947 ; Northfield, 1940 ; Oscherwitz and Davidoff, 1947 ; Russell and Nevin, 1940 ; Ward and Horton, 1940 ; Wolfe and France, 1949 ; Worster-Drought and Dickson, 1927). 


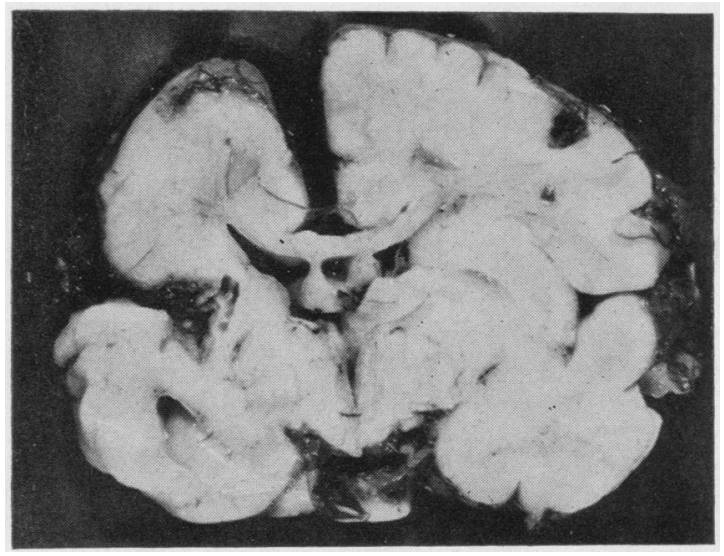

Fig. 12.-Case 3. The brain in coronal section showing atrophy and cystic degeneration of the right insula and an excess of vessels in the right lateral fissure.

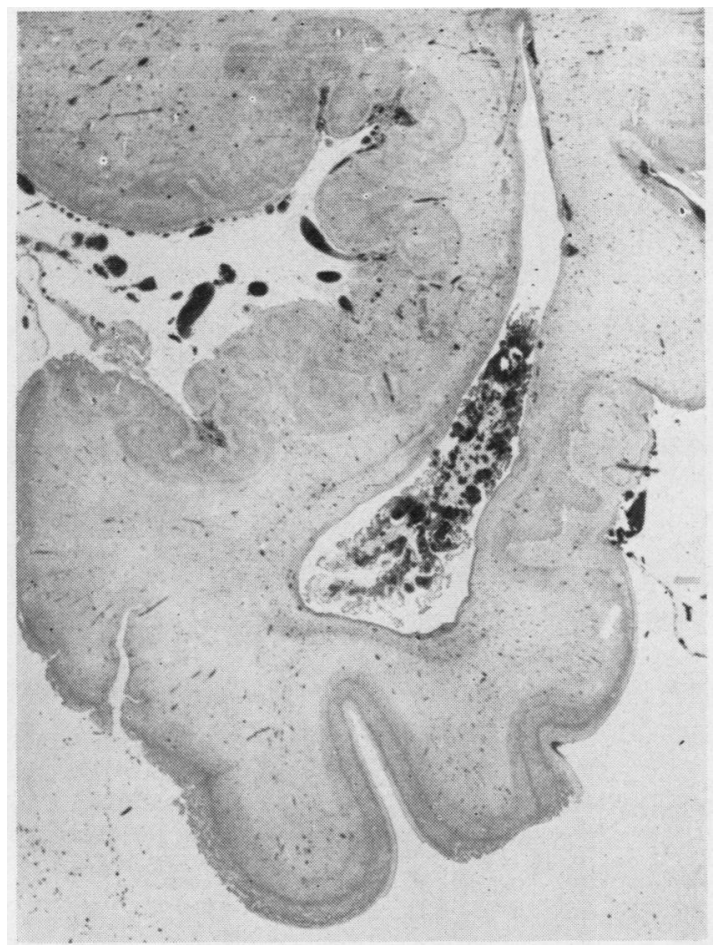

FIG. 13.-Case 3. Right lateral fissure. There are many vessels in the fissure and there is microgyria of the insula and opercula. Thick cresyl violet, $\times 3$.

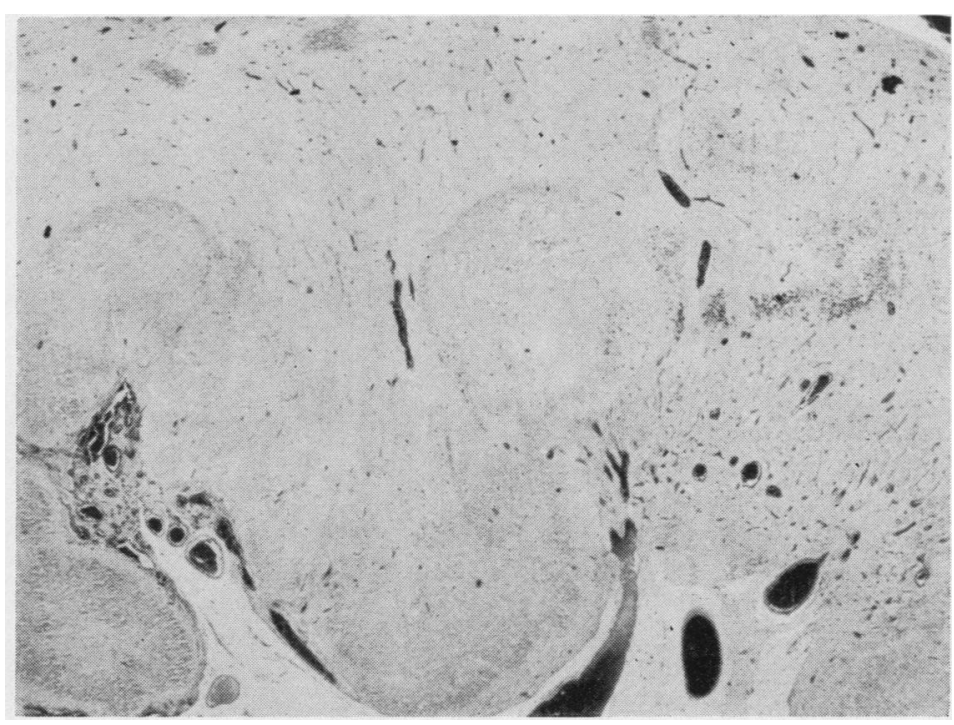

FIG. 14.-Case 3. Right insula showing the abnormal vessels entering the brain substance. The underlying white matter shows focal calcification and ectopic cortical tissue. Thick cresyl violet, $\times 12$. 
Just over $70 \%$ were male. The onset of symptoms was during the first year of life in about $25 \%$. Cerebral haemorrhage, cerebral palsies, and fits were common manifestations. Port wine angioma in the distribution of the trigeminal nerve and radiological evidence of intracranial calcification, the main features of the SturgeWeber syndrome, were observed in four of the 65 cases. A direct arteriovenous communication, shown by bruit, pulsation at operation, or postmortem dissection, was present in about $60 \%$ of the cases, but cardiac enlargement has not commonly been recorded. Heart failure was recorded only once, in a boy aged 10 years with an associated angioma of the retina (Northfield, 1940), but the presence of congestive cardiac failure in another two patients described in this paper suggests that heart failure may be commoner than supposed.

A large proportion of the angiomas, about onethird, was paracentral; other parts of the cerebrum were less commonly involved and only three were cerebellar. Extensive lesions may cover the whole of the cerebrum or one cerebral hemisphere. Dandy (1928) reported a case of bilaterally symmetrical venous angiomas in the central sulci, but multiple lesions appear to be distinctly uncommon. The vein of Galen was affected in 10 cases and in nine of these compressed the aqueduct and caused hydrocephalus.

The histological appearances are well described by Arieti and Gray (1944), Buckley (1928), and Cushing and Bailey (1928). The main features of the abnormal vessels are intimal thickening, aneurysmal out-pocketing and splitting of the elastica, sometimes with calcification. The vessels are described as being situated within the pia arachnoid, and penetration of the brain substance as in Case 3 has been reported only once (Byrnes and Boellaard, 1958). Degenerative changes in the related brain substance, observed in all three cases in this paper, are common in detailed histological reports (Arieti and Gray, 1944 ; Buckley, 1928 ; Cushing and Bailey, 1928) ; they consist of extensive gliosis, cystic change, and foci of calcification. Microgyria has not been previously reported in association with these lesions. The gyral pattern in Case 3 was similar to that described by Crome (1952), who noted increased vascularity of related pia arachnoid and brain. It may be of significance that microgyria was present only in Case 3, the only one in which the hamartomatous blood vessels penetrated the brain substance. Abnormal vessels penetrated the brain in the case described by Byrnes and
Boellaard (1958) and there was considerable destruction of brain tissue with almost complete obliteration of the gyral pattern; all areas of the cerebral meninges contained abnormal vessels to some extent, but only where these entered the brain were there major alterations of cortical tissue.

\section{Summary}

Intracranial racemose angiomas are described in three infants; two acted as arteriovenous fistulas and both infants died of cardiac failure, neither showing clinical evidence of neurological involvement. The third case was stillborn and malformed and there was microgyria near the angioma. The reports of 65 other cases of racemose angiomas have been studied. The lesions are commonest in infancy, tending to affect male children especially. Neurological symptoms predominate and cardiac failure is very rare, although over half have a direct arteriovenous communication. About a third are situated near the central sulcus. Cerebellar sites and multiple lesions are rare. The abnormal vessels are usually situated in the pia arachnoid. Gliosis and calcification occur in the adjacent brain substance. Microgyria has not been previously described in association with racemose angioma.

I wish to express my gratitude to Dr. A. H. Cameron and Professor A. C. P. Campbell for helpful advice and criticism in the preparation of this paper.

\section{REFERENCES}

Alpers, B. J., and Forster, F. M. (1945). Arch. Neurol. Psychiat. (Chicago), 54, 181.

Arieti, S., and Gray, E. W. (1944). Ibid., 51, 182.

Bailey, P.'(1948). Intracranial Tumors, 2nd ed. Charles C. Thomas, Springfield, Illinois.

Bodian, M., personal communication, 1958.

Boldrey, E., and Miller, E. R. (1949). Arch. Neurol. Psychiat. (Chicago), 62, 778 .

Buckley, R. C. (1928). Amer. J. Path., 4, 245.

Byrnes, R. L., and Boellaard, J. W. (1958). A.M.A. Arch. Path., 68, 23 .

Campbell, H., and Ballance, C. (1922). Lancet, 1, 10.

Craig, W. McK. (1939). Amer. Heart J., 17, 40.

Crome, L. (1952). J. Path. Bact., 64, 479.

Cushing, H. (1932). Intracranial Tumors. Charles C. Thomas, Springfield, Illinois.

and Bailey, P. (1928). Tumors Arising from the Blood-Vessels of the Brain. Charles C. Thomas, Springfield, nlinois.

Dandy, W. E. (1928). Arch. Surg. (Chicago), 17, 190 and 715.

Dandy, $\dot{R}$. (1952). Diseases of the Nervous System in Infancy, Childhood and Adolescence, 3rd ed. Thomas, Springfield, Illinois.

Jaeger, R., and Forbes, R. P. (1946). Arch. Neurol. Psychiat. (Ćhicago), 55, 591.

Lindau, A. (1931). Proc. roy. Soc. Med., $24,363$.

Lumsden, C. E. (1947). J. Path. Bact., 59, 328.

Northfield, D. W. C. (1940). Guy's Hosp. Rep., 90, 149.

Oscherwitz, D., and Davidoff, L. M. (1947). J. Neurosurg., 4, 539.

Oscherwitz, D., and Davidof, L. M. (1947). M. Neurosurg.
Russell, Dorothy S. (1931). Proc. roy. Soc. Med., 24, 383.

Russell, Dorothy S. (1931). Proc. roy. Soc. Med., 24,

Walshe, F. M. R. (1931). Quart. J. Med., 24, 587.

Ward, C. E., and Horton, B. T. (1940). J. Pediat., 16, 746.

Wolfe, H. R. I., and France, N. E. (1949). Brit. J. Surg., 37, 76.

Worster-Drought, C., and Dickson, W. E. Carnegie (1927). J. Neurol. Psychopath., 8, 19. 